\title{
NMR study of a soluble Guanylate Cyclase (sGC) human homologue: the H-NOX domain from Nostoc sp.
}

\author{
Aikaterini Argyriou', Marina Bantzi ${ }^{2}$, Athanassios Giannis ${ }^{2}$, Andreas Papapetropoulos ${ }^{1,3^{*}}$, Georgios A. Spyroulias ${ }^{1}$ \\ From 7th International Conference on cGMP Generators, Effectors and Therapeutic Implications \\ Trier, Germany. 19-21 June 2015
}

Heme-nitric oxide/oxygen binding (H-NOX) motifs can be found as proteins of approximately 200 amino acids in length or can exist as a domain within larger proteins, such as soluble guanylate cyclase. The H-NOX domain is conserved across eukaryotes and bacteria; within $\mathrm{sGC}$, the H-NOX domain functions as a sensor for the gaseous signaling agent nitric oxide (NO). Soluble guanylate cyclase (sGC) contains a heme-binding $\mathrm{N}$-terminal domain that regulates the catalytic site contained within the C-terminal end of the enzyme. sGC is a heterodimer, consisting of $\alpha 1$ or $\alpha 2$ subunit bound to $\beta 1$ and catalyzes the conversion of GTP to GMP. Activation of $\mathrm{NO}$ by $\mathrm{sGC}$ increases its activity several hundred-fold, promoting vasodilation and inhibiting platelet aggregation. Under pathophysiological conditions characterized by oxidative stress, sGC suffers heme loss, becomes unresponsive to $\mathrm{NO}$ and is tagged for degradation by the ubiquitin-proteasome pathway, leading to compromised NO signaling and cardiovascular disease. Ligands, such as BAY 58-2667, activate sGC in a hemeindependent manner and protect heme-oxidized sGC from proteasome degradation. Herein, we present a preliminary NMR investigation of the conformational and electronic properties of the heme-bound H-NOX protein from Nostoc sp., which shares a $35 \%$ sequence identity with the $\mathrm{H}$-NOX domain of human sGC. Additionally, we use UVvisible and heteronuclear NMR spectroscopy in order to investigate the structural integrity, the conformational variations and the dynamics of the H-NOX polypeptide during oxidation of the Fe(II) ion, while data on the changes/ destabilization of the heme moiety upon the addition of a number of ligands and oxidizing agents (NO, BAY

\footnotetext{
* Correspondence: apapapet@upatras.gr

'Department of Pharmacy, University of Patras, GR-26504, Patras, Greece

Full list of author information is available at the end of the article
}

58-2667, ODQ) are acquired through NMR. Monitoring the dynamical behavior of the H-NOX domain and the alterations occurring in its structure triggered by the changes in the oxidation status of the $\mathrm{Fe}(\mathrm{II})$-Protporphyrin IX prosthetic group in solution by NMR, may provide valuable insights for $\mathrm{sGC}$ activation/stimulation and $\mathrm{NO}$ signaling.

\section{Acknowledgments}

We acknowledge partial support from EU FP7-REGPOT-2011 "SEE-DRUG" (nr. 285950 to A.P. \& G.S.).

\section{Authors' details}

'Department of Pharmacy, University of Patras, GR-26504, Patras, Greece. ${ }^{2}$ Institute of Organic Chemistry, Leipzig University, D-04103 Leipzig, Germany. ${ }^{3}$ School of Health Sciences, Faculty of Pharmacy, University of Athens, GR-15 771, Athens, Greece.

Published: 2 September 2015

doi:10.1186/2050-6511-16-S1-A73

Cite this article as: Argyriou et al:: NMR study of a soluble Guanylate Cyclase (sGC) human homologue: the H-NOX domain from Nostoc sp. BMC Pharmacology and Toxicology 2015 16(Suppl 1):A73.

Submit your next manuscript to BioMed Central and take full advantage of:

- Convenient online submission

- Thorough peer review

- No space constraints or color figure charges

- Immediate publication on acceptance

- Inclusion in PubMed, CAS, Scopus and Google Scholar

- Research which is freely available for redistribution 